Thorax, 1980, 35, 158-159

\title{
Primary melanocarcinoma of the lower respiratory tract
}

\author{
A J ROBERTSON, D J M SINCLAIR, P P SUTTON, AND W GUTHRIE \\ From the Department of Pathology, University of Dundee, and the \\ Department of Respiratory Diseases, Kings Cross Hospital, Dundee
}

Primary melanocarcinoma of the trachea and bronchi is extremely rare: in only four of the 16 patients previously reported was the possibility of an alternative primary site excluded by necropsy. We present the clinical and necropsy findings in a further case with some unusual histological features and a family history of melanocarcinoma.

\section{Case report}

A 70-year-old woman presented in May 1978 with a 12-month history of increasing exertional dyspnoea, a non-productive cough for three months but no history of haemoptysis, loss of weight, or dysphagia. She had smoked 10 cigarettes daily until 1958 . There was no previous medical history of note but her daughter had died aged 31 years from disseminated melanocarcinoma after removal of a cutaneous primary from the calf. The patient's general condition was good, with minimal stridor but no finger clubbing or lymphadenopathy; reduced percussion note and breath sounds with associated wheezes were noted over the right midzone anteriorly. Chest radiography showed a dense mass in the right middle lobe, enlargement of the right hilum, and an abnormal paratracheal shadow. Numbers of darkly pigmented cells were seen on sputum cytology. Fibreoptic bronchoscopy revealed extensive black discolouration and swelling of the mucosa at the carina spreading down both main bronchi, the lumen being almost totally occluded on the right side. A biopsy showed diffuse infiltration of the bronchial mucosa by melanocarcinoma. No alternative primary was found on clinical examination and there was no history of spontaneous regression or surgical removal of a pigmented lesion. A divided four week course of radiotherapy was given with considerable symptomatic relief, but no improvement in either the radiological or bronchoscopic appearances. She died nine weeks after presentation having developed mediastinal emphysema and bronchopneumonia.

\section{PATHOLOGICAL FINDINGS}

At necropsy, the right middle lobe was found to be widely infiltrated by solid black neoplasm as were the carina, right main bronchus, middle lobe bronchus and its medial segmental branch, and the proximal

Address for reprint requests: Dr AJ Robertson, Department of Pathology, University of Dundee, Dundee.
$3 \mathrm{~cm}$ of the left main bronchus (fig 1). The hilag lymph nodes were massively replaced by the neq plasm which had also ulcerated through the oesor phageal mucosa $2.5 \mathrm{~cm}$ below the level of the carine Direct extension had occurred anteriorly to involve the fourth and fifth intercostal spaces, and metastases were seen in the right axillary and internat mammary lymph nodes. The liver and the ninf thoracic vertebra each contained a solitary 1.5 c metastasis. The nasal cavities, meninges, and eyes (both of which were sectioned) showed no neoplasm.

Microscopy showed the neoplasm to be arranged in whorls and strands and to consist mainly of spindle shaped melanocytes containing varying amounts of melanin pigment and with oval, often vesiculate nuclei (fig 2). In some areas dendritic cells pres dominated, while in others multinucleated neoplast giant cells were prominent: mitoses were scant\% Heavily pigmented melanophores were abunda throughout the neoplasm.

\section{Discussion}

Primary melanocarcinoma of the lower respirato tract is extremely rare. Of the sixteen cases des: cribed in the literature only four ${ }^{1-4}$ entirely excluded an alternative primary neoplasm by necropsy exani ination. It is likely that these neoplasms arise frop neuroectodermal melanoblasts which have emigrated to the respiratory mucosa during early embryon development. The respiratory tract develops as downgrowth from the foregut and hence it is rather surprising that melanocarcinomas are not seen more frequently in the bronchial tree, as is indeed the case for the oesophagus and nasopharynx. Although met anoblasts have been identified in the normal oes phageal epithelium, ${ }^{5}$ no such study has been performest on respiratory mucosa.

Most reported bronchial melanocarcinomas ha arisen in the large central bronchi where they preserab as dark brown, usually polypoidal, growths. The patients present with a short history of couge haemoptysis, or dyspnoea as their main symptoms Bronchoscopy and biopsy are essential to establish the diagnosis but sputum cytology may also be of benefit, as in our case. Occasional patients have survived u⿺ to 11 years after lobectomy or pneumonectomy, but most pursue a rapid downhill course until their dea within months of initial presentation.

In our case the neoplasm was rather unusual histo logically in that it showed several features mote 


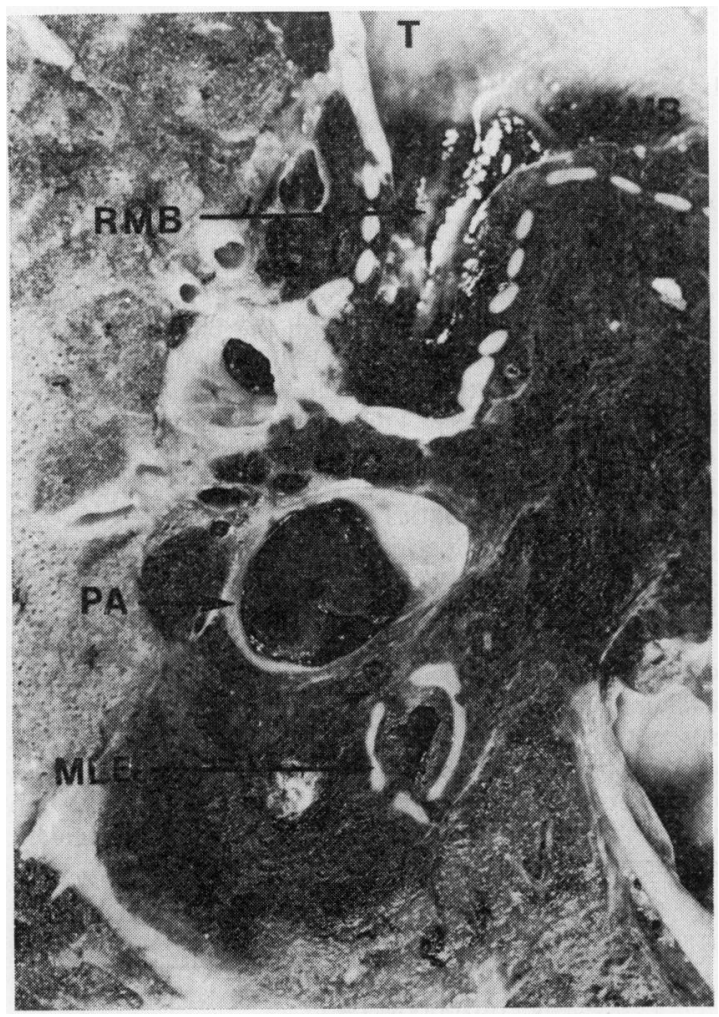

Fig 1 Coronal section through right hilum showing melanocarcinoma in the trachea $(T)$, both main bronchi $(R M B$ and $L M B)$, and medial segment of the middle lobe bronchus $(M L B)$. There is infiltration of the middle lobe (bottom left) and the hilar nodes. The right pulmonary artery $(P A)$ is occluded by thrombus. Original magnification $\times 2$.

commonly associated with a malignant blue naevusabsence of junctional activity, the presence of dendritic and spindle-shaped cells, and a relative paucity of mitotic activity. We ultimately decided, nevertheless, that the most appropriate diagnosis was that of melanocarcinoma. Of further interest was the family history of this neoplasm. The occurrence in more than one member of a family of skin melanocarcinoma is well recognised: this is the first report of familial melanocarcinoma in which a bronchial primary has been demonstrated.

We thank Professor J Swanson Beck and Dr RN Johnston for their helpful advice with the manuscript, and Mr R Fawkes for the photography.

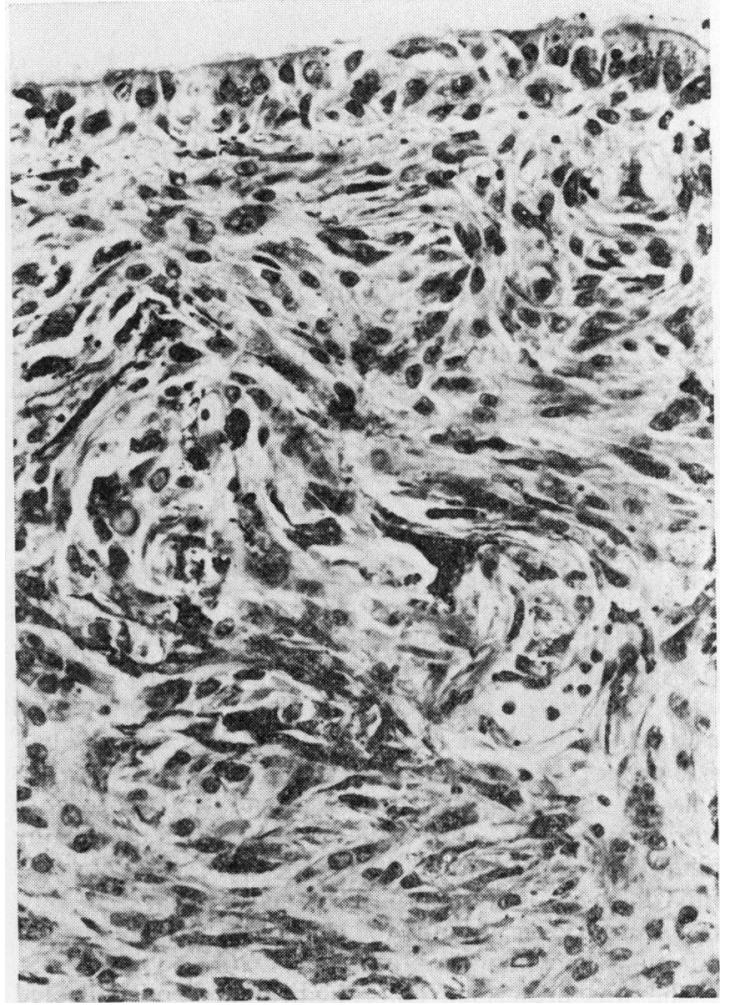

Fig 2 Photomicrograph showing bronchial mucosa infiltrated by melanocarcinoma consisting of spindle and dendritic cells. There is no evidence of junctional activity. (Haematoxylin and Eosin, original magnification $\times 400$ ).

\section{References}

1 Salm R. A primary malignant melanoma of the bronchus. J Pathol Bacteriol 1963; 85:121-6.

2 Reid JD, Mehta VT. Melanoma of the lower respiratory tract. Cancer 1966; 19:627-31.

3 Jensen OA, Egedorf J. Primary malignant melanoma of the lung. Scand J Respir Dis 1967; 48: 127-35.

4 Walter P, Fernandes C, Florange W. Melanome malin primitif pulmonaire. Ann Anat Pathol 1972; 17:91-9.

5 De La Pava S, Nigogosyan G, Pickren JW, Cabrera A. Melanosis of the oesophagus. Cancer 1963; 16:48-50. 